\section{A) Check for updates}

Cite this: Inorg. Chem. Front., 2020, 7, 2305

Received 7th December 2019, Accepted 31st March 2020

DOI: 10.1039/c9qi01606f

rsc.li/frontiers-inorganic

\title{
Exploiting cation aggregation in new magnesium amidohaloaluminate electrolytes for magnesium batteries $\uparrow$
}

\author{
Etienne V. Brouillet, ${ }^{a}$ Marco Amores, (D) ${ }^{b}$ Serena A. Corr (D)*c,d and \\ Stuart D. Robertson (iD *a
}

\begin{abstract}
Mg batteries present an attractive and sustainable alternative to Li-ion batteries, wherein magnesium metal as an anode displays a superior theoretical volumetric energy density of $3833 \mathrm{~A} \mathrm{~h} \mathrm{~L}^{-1}$ versus $2062 \mathrm{~A}$ $\mathrm{h} \mathrm{L}^{-1}$ for lithium. An outstanding crucial bottleneck in realising their more widespread uptake is the development of suitable electrolytes, where electrode passivation, a limited electrochemical window, conditioning requirements, low ion mobility and low coulombic efficiencies all contribute to current limitations in $\mathrm{Mg}$ batteries. In an area thus far dominated by the thermodynamically stable $\left[\mathrm{Mg}_{2} \mathrm{Cl}_{3}\right]^{+}$dinuclear cation, we present here a novel family of magnesium amidohaloaluminate electrolytes [(Dipp) $\left.\left(\mathrm{SiMe}_{3}\right)_{2} \mathrm{NAlCl}_{3}\right]^{-}\left[\mathrm{Mg}_{x} \mathrm{Cl}_{2 x-1}\right]^{+}$where the magnesium chloride cation aggregation has been tailored $(x=1$, $2,3)$ by substitution of the coordinating ligand to the $\mathrm{Mg}^{2+}$ centre, and show how directly altering this cation affects battery performance (Dipp = 2,6-diisopropylphenyl, $\mathrm{Me}=$ methyl). The electrochemical activity of these new electrolytes has been evaluated by cyclic voltammetry, galvanostatic cycling and impedance spectroscopy in $\mathrm{Mg}$-metal symmetrical cells as well as in battery cells with the $\mathrm{Mo}_{6} \mathrm{~S}_{8}$ Chevrel phase cathode material against magnesium metal. The mononuclear and dinuclear magnesium amidohaloaluminate electrolytes facilitate reversible $\mathrm{Mg}$ plating and stripping from the $\mathrm{Mg}$-metal anode with excellent stability, withstanding over 70 hours of continuous cycling. We demonstrate the compatibility of these novel electrolytes with the $\mathrm{Mo}_{6} \mathrm{~S}_{8}$ Chevrel intercalation cathode material, allowing cycling of a Mgmetal cell up to 100 cycles with coulombic efficiencies above $95 \%$.
\end{abstract}

\section{A. Introduction}

The current rechargeable battery market is heavily reliant on lithium (Li)-ion chemistry, with Li-ion batteries ubiquitous in our portable devices and increasingly prevalent in powering (hybrid) electric vehicles. ${ }^{1,2}$ However, with increasing demands on our lithium supply driving up costs, it is vital alternatives to Li-ion chemistries are sought. ${ }^{3}$ Increasingly, efforts have been made in developing multivalent Group II battery chemistries that can achieve high volumetric capacities using lower

\footnotetext{
${ }^{a}$ WestCHEM, Department of Pure and Applied Chemistry, University of Strathclyde, Glasgow G1 1XL, UK. E-mail: stuart.d.robertson@strath.ac.uk

${ }^{b}$ Department of Chemistry, Graduate School of Science, The University of Tokyo, 7-31, Hongo, Bunkyo-Ku, Tokyo, 113-0033, Japan

${ }^{c}$ Department of Chemical and Biological Engineering, University of Sheffield,

Sheffield S1 3JD, UK. E-mail: s.corr@sheffield.ac.uk

${ }^{d}$ Department of Materials Science and Engineering, University of Sheffield, Sheffield S1 3JD, UK

$\dagger$ Electronic supplementary information (ESI) available: Experimental details, further electrochemical characterisation, X-ray diffraction, electron microscopy and EDX mapping. See DOI: 10.1039/c9qi01606f
}

cost, highly-abundant metals. ${ }^{4}$ Of these, magnesium is a particularly attractive candidate owing to a combination of its relatively light weight and massively higher natural abundance (compared to Li). ${ }^{5,6}$ The redox process of divalent magnesium ions $\left(\mathrm{Mg}^{2+}\right)$ proceeds via a two-electron transfer, bestowing on magnesium a theoretical volumetric capacity almost twice that of lithium (3833 A h L ${ }^{-1} c f .2062 \mathrm{~A} \mathrm{~h} \mathrm{~L} \mathrm{~L}^{-1}$ ). The negative reduction potential of magnesium at $-2.37 \mathrm{~V}$ ( $v s$. SHE) makes it a viable option for exploiting useful voltages. Despite these considerable advantages, impediments remain in the advancement of Mg-batteries and chief amongst these is the development of $\mathrm{Mg}$-based electrolytes that enable reversible plating and stripping of $\mathrm{Mg}^{2+}$ on the $\mathrm{Mg}$-metal anode. For example, the use of $\mathrm{Mg}$ inorganic salts, analogous to lithium electrolytes, in aprotic solvents leads to the formation of impermeable passivating layers at the electrode interface. ${ }^{7,8}$ Interestingly, the key to unlocking this early $\mathrm{Mg}$ electrolyte problem was the use of Grignard reagents, which enables passivating layer-free reversible electrodeposition in ethereal solvents. $^{9}$ The strong reducing nature of Grignard reagents, which affects the electrochemical window dramatically, was 
simply overcome by addition of a group 13 Lewis acid, generating ionic bimetallic complexes such as magnesium aluminates. ${ }^{5}$ The active species of these compounds typically adopts the form of the solvent-separated ion pair $\left[\mathrm{Mg}_{2} \mathrm{Cl}_{3} \cdot 6 \mathrm{THF}\right]^{+}$ $\left[\mathrm{R}_{x} \mathrm{AlCl}_{4-x}\right]^{-}$in THF. ${ }^{10,11}$ Since the first prototype of a rechargeable magnesium battery and the characterisation of the purported active species of these magnesium aluminate electrolytes, a variety of analogous electrolytes have been proposed. The anion $\left[\mathrm{R}_{x} \mathrm{AlCl}_{4-x}\right]^{-}$may be easily modified using different $\mathrm{R}$ groups, and by introducing halide, alkyl, aryl, amido or alkoxide ligands to the aluminium metal centre. ${ }^{10-16}$ These studies revealed evidence that the nature of the Al- $\mathrm{R}$ bond is key to a number of properties, such as the solubility, nucleophilicity and oxidative stability. ${ }^{17}$ In almost all of these case studies, the cation adopts the thermodynamically-favoured dinuclear magnesium cation $\left[\mathrm{Mg}_{2} \mathrm{Cl}_{3} \cdot 6 \mathrm{THF}\right]^{+}$. We recently published a synthetic method to access magnesium aluminate compounds with a common aluminate anion and the ability to control the aggregation level of the magnesium cation through judicious choice of Lewis donor in both solid state and solution, observed by means of X-ray crystallography and electrospray-ionization mass spectrometry (ESI-MS) (Fig. 1). ${ }^{15}$ These cationic species include mononuclear $[\mathrm{MgCl}]^{+}$and trinuclear $\left[\mathrm{Mg}_{3}\left(\mu^{3}-\mathrm{Cl}\right)_{2}\left(\mu^{2}-\mathrm{Cl}\right)_{3}\right]^{+}$aggregates, whose existence in the electrolyte solution were previously postulated as playing an important role in $\mathrm{Mg}$ deposition when using a formally $\left[\mathrm{Mg}_{2} \mathrm{Cl}_{3}\right]^{+}$based electrolyte. ${ }^{18-20}$ With these three cation aggregation states to hand (accompanied by a common aluminate counteranion), the potential to investigate the effect of cation aggregation on electrolyte performance is now available. We now report the battery performances using these compounds as electrolytes in $\mathrm{Mg}-\mathrm{metal} / \mathrm{Mo}_{6} \mathrm{~S}_{8}$ battery cells and interpret the different experimental results in order to identify which
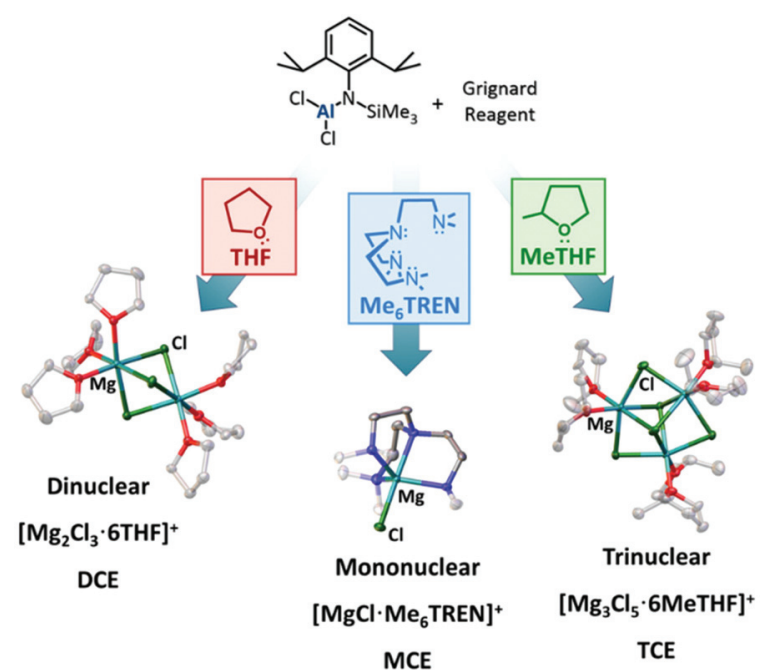

Fig. 1 Schematic representation of the synthetic approach for the preparation of magnesium amidohaloaluminate complexes and the different aggregations of the $\left[\mathrm{Mg}_{x} \mathrm{Cl}_{2 x-1}\right]^{+}$cations depending on the coordinating ligand. The $\left[(\mathrm{Dipp})\left(\mathrm{SiMe}_{3}\right) \mathrm{NAlCl}_{3}\right]^{-}$counteranion is not shown for clarity. aggregation is more beneficial to $\mathrm{Mg}^{2+}$ ion transfer, plating/ stripping and intercalation. We have selected the $\mathrm{Mo}_{6} \mathrm{~S}_{8}$ Chevrel phase as a robust cathode material which has been widely studied in the literature, but it is interesting to note recent developments in high-performance cathodes such as $\mathrm{MgTi}_{2} \mathrm{~S}_{4}$ which display improved properties. ${ }^{21,22}$ We show that all three electrolytes possess individual properties which affect the plating/stripping of $\mathrm{Mg}$, electrochemical stability window, ionic conductivity, gravimetric specific capacity and overpotential of battery cells. The presence of different Lewis donors, particularly tetraamine $\mathrm{Me}_{6}$ TREN (tris[2-(dimethylamino)ethyl] amine $\left.\mathrm{N}\left(\mathrm{CH}_{2} \mathrm{CH}_{2} \mathrm{NMe}_{2}\right)_{3}\right)$, is suspected to affect the electrochemical window by enhancing the oxidative stability of the electrolyte, with electrolyte conditioning required before achieving optimal performance.

\section{B. Results}

Electrolyte complexes possessing the mononuclear (MCE), dinuclear (DCE) and trinuclear (TCE) magnesium chloride cation aggregations in conjunction with the common aluminate anion $\left[(\mathrm{Dipp})\left(\mathrm{SiMe}_{3}\right) \mathrm{NAlCl}_{3}\right]^{-23}$ were synthesised according to the methodology previously developed in our group. ${ }^{15}$ The main prerequisite for a candidate electrolyte in a secondary metal-anode battery is the ability to reversibly plate and strip metal ions at the metal anode surface. To evaluate this plating and striping behaviour of the three magnesium amidohaloaluminate complexes presented here, polarisation tests of symmetrical cells with $\mathrm{Mg}$-metal electrodes were performed (Fig. 2). During the first current pulse, the three electrolytes display a voltage peak which starts to decrease rapidly over the first 30 minutes. These observations may be attributed to elec-

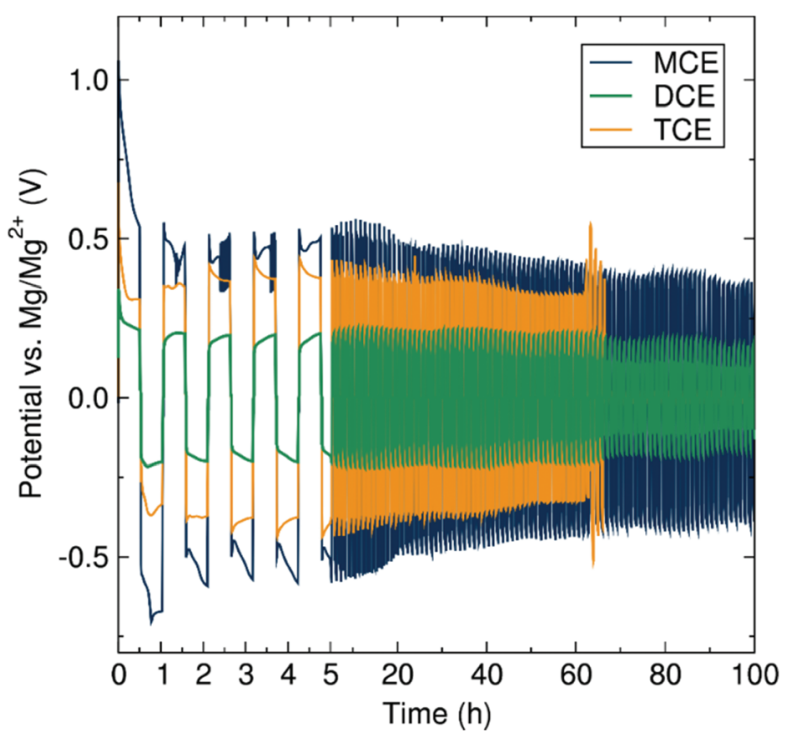

Fig. 2 Polarisation measurements of symmetrical cells with $\mathrm{Mg}$-metal electrodes and the three magnesium aluminate electrolytes (MCE, dark blue; DCE green; TCE orange) with different $\mathrm{Mg}^{2+}$ aggregation states at current densities of $200 \mu \mathrm{A} \mathrm{cm}^{-2}$. 
trolyte conditioning, where the electrolyte is believed to undergo structural adjustments during the cycling process, generating new species facilitating the reversible deposition of Mg. Further work is ongoing to elucidate these species. The conditioning of magnesium electrolytes has been reported in the literature, for example on the fully inorganic magnesium aluminium chloride-complex (MACC). ${ }^{19,24-27}$ In the subsequent pulses, the voltage of the cell using either MCE or DCE electrolytes stabilises at $c a .0 .37$ and $0.12 \mathrm{~V}$ respectively, while the TCE experiences a voltage at $c a$. $0.37 \mathrm{~V}$ which rises over cycling. The increase in cell voltage when TCE is used is indicative of a higher resistance toward plating and stripping of $\mathrm{Mg}$ which increases with the amount of $\mathrm{Mg}$ transferred from one electrode to the other. With MCE and DCE, the average cell polarisation voltage is constant during the experiment, indicating the excellent stability of the electrolyte upon $\mathrm{Mg}$ transference. The TCE electrolyte, however, suffers sudden voltage variations after 65 hours, followed by short-circuiting of the cell. Such soft short-circuiting, owing to dendrite growth, has also previously been observed for $\mathrm{Mg}(\mathrm{TFSI})_{2} /$ glyme electrolytes via CV and EIS experiments. ${ }^{28}$ After disassembling the short-circuited battery cell, we observed unusual deposition occurring through the separator. We therefore link this short-circuit phenomenon to a higher predisposition of TCE to form localised deposits of $\mathrm{Mg}$ being entropically favoured by the higher aggregation number, as can be appreciated by metallic grey deposits on the separator after the polarisation test (Fig. S1†). Similar deposits were not observed in the case of the MCE or DCE electrolytes. We note here that Mg electrolytes are generally accepted as prohibiting dendrite formation although Banerjee et al. have recently reported dendrite formation when using Grignard reagents in symmetric $\mathrm{Mg}-\mathrm{Mg}$ cells. ${ }^{29}$ All three cell measurements here have been performed using identical setup conditions in order to reliably and directly determine and compare the resistance properties of each electrolyte from the polarisation voltage. The results (in Fig. 2) clearly show the effect of the cation aggregation state on the impedance of the cell, where the cell resistance after cycling is significantly lower when the mononuclear and dinuclear cations are involved compared to the presence of the more highly aggregation-prone trinuclear cation species. The concentration of the magnesium aluminate salt used in the electrolyte solution is determined according to the concentration of $\mathrm{Mg}^{2+}$ ions, where a desired concentration of $0.35 \mathrm{M}$ $\mathrm{Mg}^{2+}$ means a decreasing concentration of the salt with increasing cation aggregation (MCE 0.35 M; DCE 0.175 M; TCE $0.117 \mathrm{M})$. Considering these circumstances for the current study, we are aware that the higher dilution of the DCE and TCE salt could affect the transport and aggregation properties of the cationic species in solution. However, from a previous study using ESI-MS, the change of concentration only has a minor impact on the ratio of the higher aggregation states of the cation. ${ }^{15}$

Electrochemical Impedance Spectroscopy (EIS) analyses were carried out before and after cycling of the symmetrical cells to fully analyse and differentiate the transport properties of the electrolytes. From the Nyquist plots displayed in Fig. 3, the charge transfer process occurring at the $\mathrm{Mg}$-metal/electrolyte interface is represented by a semicircle. The intercept of the semicircle at high frequencies corresponds to the pure Ohmic resistance of the separators soaked in the electrolyte solutions. At lower frequencies, the starting point of the semicircle represents the ionic transport properties of the electrolyte. While the ionic transport properties of the electrolyte remain on the same order of magnitude for the three electrolytes before and after the polarisation test (40-80 Ohms), the charge transfer resistance experiences a clear decrease after cell cycling, indicating that the electrolyte conditioning is directly related to charge transfer at the $\mathrm{Mg}$-metal surface.
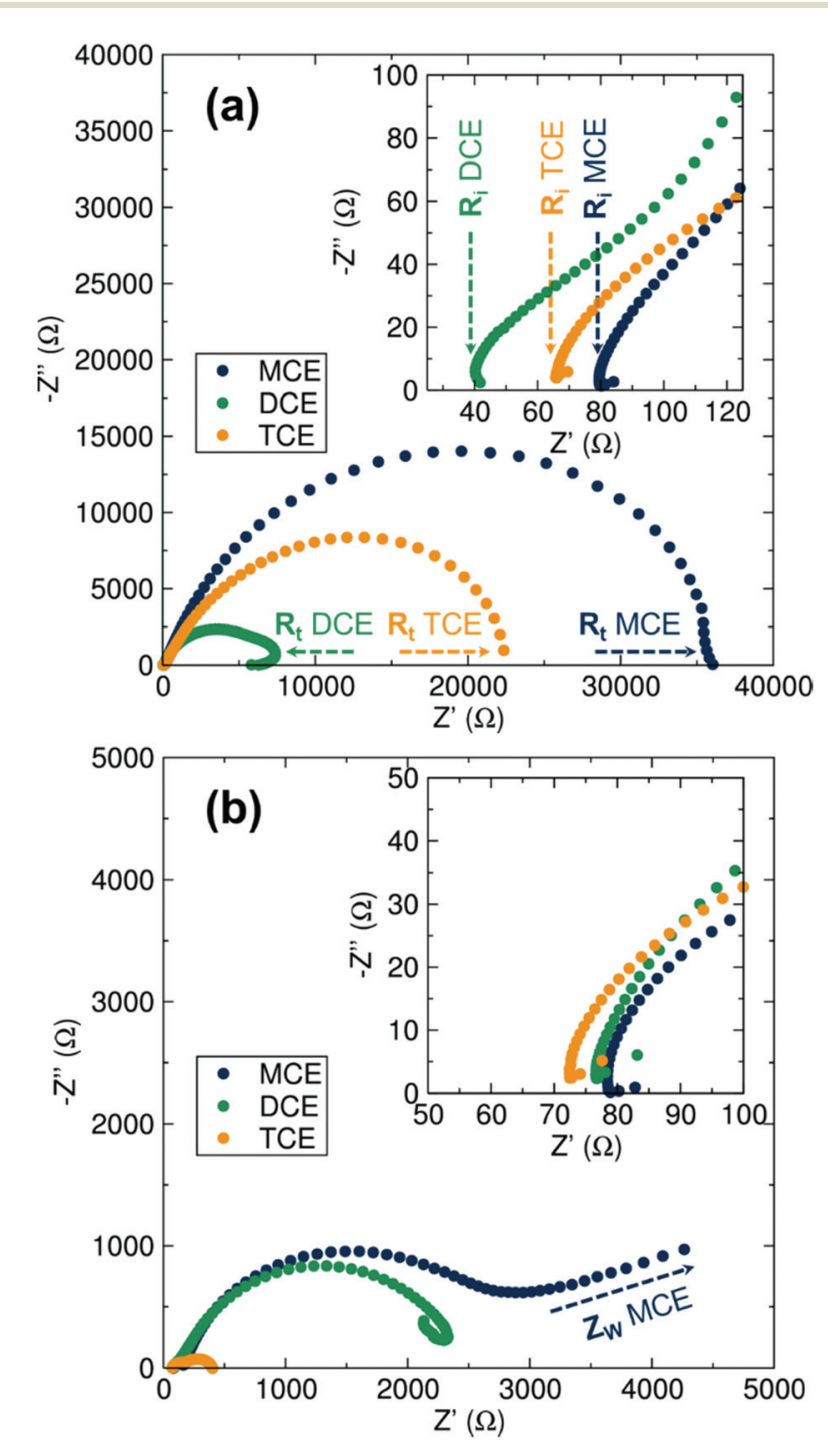

Fig. 3 Nyquist plot of the EIS data of three different electrolytes (MCE, dark blue; DCE green; TCE orange) in Mg-metal symmetrical cells before (a) and after (b) the polarisation tests. The electrolytes resistance in the separators is indicated by the $R_{\mathrm{i}}$ label, while the total resistance of the cell including the charge transfer and any contribution from possible passivation layer is labelled as $R_{\mathrm{t}}$. The appearance of a Warburg impedance contribution is labelled as $Z_{\mathrm{w}}$. 
This large decrease can be correlated to a variety of possible electrolyte rearrangements at the $\mathrm{Mg}$-metal/electrolyte interface in order to facilitate the plating/stripping mechanism. Such rearrangements would include previously reported processes responsible for the promotion of $\mathrm{Mg}$ deposition, mainly $\mathrm{Cl}^{-}$adsorption onto the $\mathrm{Mg}$ anode but also the different aggregation states of the magnesium chloride cations found in solution where a mononuclear cation is favourable. ${ }^{19,25-27,30,31}$ In agreement with polarisation tests, DCE displays the lowest impedance both before and after the polarisation measurements (note the impedance of TCE in Fig. 3b is that of the short-circuited cell).

To establish the performance of these electrolytes for future $\mathrm{Mg}$ battery applications, battery cells comprising each candidate electrolyte, together with a $\mathrm{Mg}$-metal anode and the $\mathrm{Mo}_{6} \mathrm{~S}_{8}$ Chevrel phase cathode material, were analysed by cyclic voltammetry (CV) and galvanostatic cycling measurements. The previously studied $\left[\mathrm{Mg}_{2} \mathrm{Cl}_{3} \cdot 6 \mathrm{THF}\right]^{+}\left[(\mathrm{HMDS}) \mathrm{AlCl}_{3}\right]^{-}$electrolyte $\left(\mathrm{HMDS}=\right.$ hexamethyldisilazide, $\left.\mathrm{N}\left(\mathrm{SiMe}_{3}\right)_{2}\right)$ was also studied in identical full cells as a benchmark for the electrochemical properties of the Chevrel phase (Fig. S2†). ${ }^{11,14}$

The stability and compatibility of each electrolyte with the $\mathrm{Mo}_{6} \mathrm{~S}_{8}$ Chevrel phase electrode material was first examined by means of CV experiments. MCE exhibits a robust stability up to $2.5 \mathrm{~V}$ with a relatively slow conditioning requirement, showing the defined redox peak of the Chevrel phase at cycle 40 (Fig. 4a). As previously noted, the electrolyte conditioning of the fully inorganic dinuclear cation-based electrolyte MACC has been reported and was attributed to the adjustment of the $\mathrm{Mg}$ : Al stoichiometry which allows for a degree of control over magnesium chloride cation aggregate formation. ${ }^{19,25}$

While the chloride ligands are almost exclusively involved in driving towards equilibrium in the MACC system, we postulate that the conditioning of MCE here proceeds via a different route involving rearrangements associated with both the (Dipp)N( $\left.\mathrm{SiMe}_{3}\right)$ amide and the $\mathrm{Me}_{6}$ TREN species. Our previous work identified the species present in a THF solution of MCE by ESI-MS where, apart from the X-ray characterised mononuclear cation $\left[\mathrm{MgCl} \cdot \mathrm{Me}_{6} \mathrm{TREN}\right]^{+}$, the $\mathrm{Me}_{6} \mathrm{TREN}$ coordinated dinuclear cation $\left[\mathrm{Mg}_{2} \mathrm{Cl}_{3} \cdot 2 \mathrm{Me}_{6} \mathrm{TREN}\right]^{+}$was also observed. The formation of a trinuclear magnesium cation aggregate in the presence of $\mathrm{Me}_{6}$ TREN seems unlikely, but the accessibility of the dinuclear cation, presumably due to the lability of the $\mathrm{Me}_{6}$ TREN arms, could potentially play a role in this conditioning mechanism..$^{32-34}$ In the case of DCE, a sudden increase in the current was observed above $1.8 \mathrm{~V}$, and is likely due to electrolyte decomposition (Fig. 4b). The electrochemical stability window of DCE is large enough to cycle the Chevrel phase, which displays an average charging voltage of $1.5 \mathrm{~V} v s . \mathrm{Mg} /$ $\mathrm{Mg}^{2+}$. When operating the cell within this window, the redox peaks of the Chevrel phase with DCE appear well defined from the second cycle, indicative of a conditioning-free electrolyte. In regard to TCE, the $\mathrm{CV}$ reveals a decomposition voltage comparable to DCE at ca. $2 \mathrm{~V}$ (Fig. 4c), but after a short conditioning phase well-defined redox peaks are observed. The conditioning requirements are in line with observations from impedance measurements in symmetrical cells prior to cycling, following the trend of highest resistance requiring greater conditioning need: MCE displays the highest resistance of $36 \mathrm{k} \Omega$ and requires the strongest need for conditioning, followed by TCE which possesses a more modest need for conditioning and a resistance of $22 \mathrm{k} \Omega$ and finally DCE which has no apparent need for conditioning and a resistance of $7.4 \mathrm{k} \Omega$. The oxidative stability of DCE and TCE is lower than its closest kin in the literature, $\left[\mathrm{Mg}_{2} \mathrm{Cl}_{3} \cdot 6 \mathrm{THF}\right]^{+}\left[(\mathrm{HMDS}) \mathrm{AlCl}_{3}\right]^{-}$(with a $\mathrm{CV}$ of this electrolyte presented in Fig. S2 in the ESI $\dagger$ ). We suspect that the increased steric profile of our aryl/silyl amide with respect to HMDS weakens both the Al-N and $\mathrm{N}-\mathrm{Si}$ bonds and decreases the stability of the complex, while the different electronic properties contribute further to this since it lacks the stabilisation of the two $\mathrm{N}-\mathrm{Si}$ bonds emerging from the symmetry of the disilazide moiety present in HMDS. MCE possesses an oxidative stability approximately $1.0 \mathrm{~V}$ higher than both DCE and TCE and we associate this with the presence of $\mathrm{Me}_{6}$ TREN, which can potentially interact with the aluminium anion during electrolyte conditioning. The interactive aptitude of the tetraamine ligands can be illustrated by previous studies which showed that in the presence of acid traces, new species such as $\left[\mathrm{MgCl} \cdot \mathrm{Me}_{6} \mathrm{TREN}\right] \cdot \mathrm{HCl}^{+}$were observed. ${ }^{15}$ Knowing the strong Lewis acidic nature of $\mathrm{AlCl}_{3}$ and related compounds, it
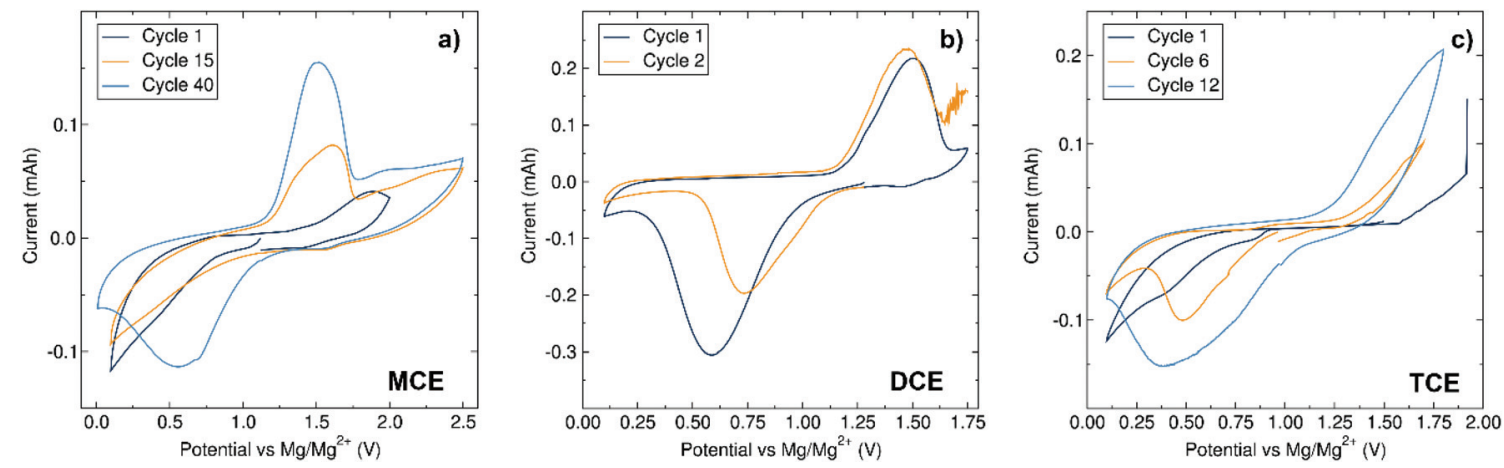

Fig. 4 Cyclic voltammograms of $\mathrm{Mg} / \mathrm{Mo}_{6} \mathrm{~S}_{8}$ cells at scan rates of $0.1 \mathrm{mV} \mathrm{s}^{-1}$ using (a) MCE $0.35 \mathrm{M}$ in THF, (b) DCE $0.175 \mathrm{M}$ in THF and (c) TCE 0.117 $M$ in MeTHF. 
would not be unexpected to consider an interaction between a $\mathrm{Me}_{6} \mathrm{TREN}$ unit and $\left[(\mathrm{Dipp})\left(\mathrm{SiMe}_{3}\right) \mathrm{NAlCl}_{3}\right]^{-}$. Future work includes investigating the ${ }^{29} \mathrm{Si} \mathrm{NMR}$ of the electrolytes after cycling to investigate these structural arrangements.

To evaluate the aggregation effect on the resulting capacities, galvanostatic cycling at a rate of $\mathrm{C} / 10$ was performed at room temperature (Fig. 5). All three cells were cycled between $0.2 \mathrm{~V}$ and $1.5 \mathrm{~V}$ to inhibit decomposition of the electrolytes and directly compare their capacities. The first discharge cycles for all three electrolytes give similar capacity values, ranging from ca. 125 to $145 \mathrm{~mA} \mathrm{~h} \mathrm{~g}{ }^{-1}$ which are close to the theoretical capacity value for $\mathrm{Mo}_{6} \mathrm{~S}_{8}\left(128 \mathrm{~mA} \mathrm{~h} \mathrm{~g}{ }^{-1}\right)$. The small additional capacity could arise from electrolyte decomposition or capacitive behaviour at the electrode surfaces during the first cycle. The capacity of the subsequent cycles is reduced, a phenomenon commonly observed with the Chevrel phase which is known to trap some $\mathrm{Mg}^{2+}$ ions within the host structure after the first cycle. $^{35-37}$ In agreement with the results observed from CV experiments, MCE displays slow conditioning behaviour, with capacities below $20 \mathrm{~mA} \mathrm{~h} \mathrm{~g}{ }^{-1}$ in the first cycles before increasing to $\sim 70 \mathrm{~mA} \mathrm{~h} \mathrm{~g}^{-1}$ after 50 cycles and maintaining a robust profile over 100 cycles. DCE shows a slow increase in discharge capacity
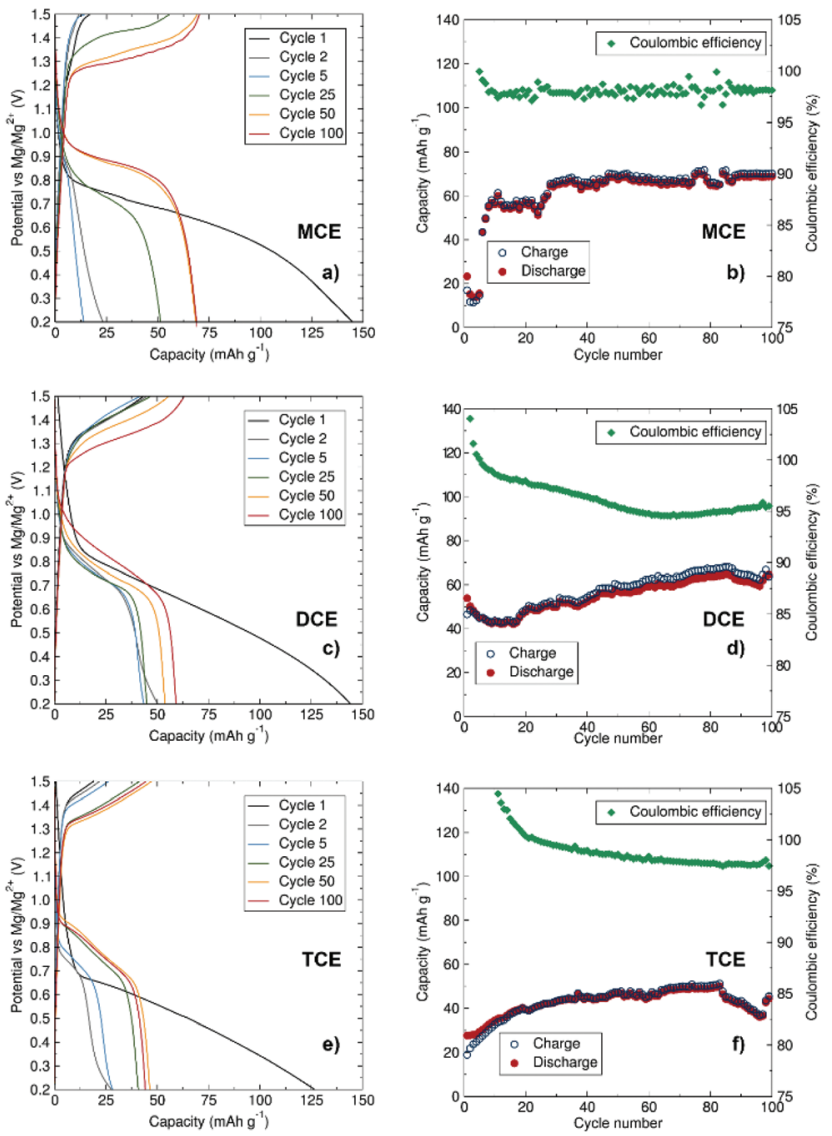

Fig. $5 \mathrm{Mg} / \mathrm{Mo}_{6} \mathrm{~S}_{8}$ cells, at a $\mathrm{C} / 10$ rate $\left(12.8 \mathrm{~mA} \mathrm{~g}^{-1}\right.$ ) (a) charge/discharge profile and (b) cyclic efficiency of $0.35 \mathrm{M} \mathrm{MCE}$ in THF; (c) charge/discharge profile and (d) cyclic efficiency of 0.175 M DCE in THF; (e) charge/discharge profile and (f) cyclic efficiency of 0.117 M TCE in MeTHF. from $\sim 45 \mathrm{~mA} \mathrm{~h} \mathrm{~g}{ }^{-1}$ up to $\sim 60 \mathrm{~mA} \mathrm{~h} \mathrm{~g}{ }^{-1}$ after 100 cycles. Comparatively, the charge/discharge performance in terms of capacity is lowest for TCE in MeTHF, with capacities not exceeding $50 \mathrm{~mA} \mathrm{~h} \mathrm{~g}{ }^{-1}$ after 100 cycles. The TCE system shows the least pronounced increase in specific capacity with conditioning, from 27 to $50 \mathrm{~mA} \mathrm{~h} \mathrm{~g}{ }^{-1}$. This electrolyte displays a slower conditioning process and less consistent capacity retention compared to MCE and DCE. The larger size of the trinuclear cation $\left[\mathrm{Mg}_{3} \mathrm{Cl}_{5} \cdot 6 \mathrm{MeTHF}\right]^{+}$is a potential hindrance to ionic diffusion and mobility of the active species in MeTHF. The volume of the crystallographically characterised cations increases as follows: $\left[\mathrm{MgCl} \cdot \mathrm{Me}_{6} \mathrm{TREN}\right]^{+}\left(256.9 \AA^{3}\right),\left[\mathrm{Mg}_{2} \mathrm{Cl}_{3} \cdot 6 \mathrm{THF}\right]^{+}\left(484.8 \AA^{3}\right)$ and $\left[\mathrm{Mg}_{3} \mathrm{Cl}_{5} \cdot 6 \mathrm{MeTHF}\right]^{+}\left(621.6 \AA^{3}\right)$. The size of the ionic species in an electrolytic solution is often responsible for lowering of the ionic diffusion of the ions, reducing their mobility, hence affecting charge transfer during charging and discharging of the battery. This low ionic diffusion is compensated at higher voltage, thus the reason for the higher oxidation peak and more sluggish kinetics observed in the CV of TCE. In addition to ion mobility challenges, greater cation aggregation at the electrode/electrolyte interface can also negatively affect the battery performance, as greater energy input will be required to deposit/intercalate $\mathrm{Mg}^{2+}$ cations at this more aggregated interface.

We observe lower conductivity values for MCE, likely due to the $\mathrm{Me}_{6}$ TREN ligand coordinating more strongly compared to the THF and MeTHF molecules in DCE and TCE, respectively, thereby restricting $\mathrm{Mg}^{2+}$ diffusion in the MCE electrolyte. Similar impeded diffusion has been reported for $\mathrm{Mg}^{2+}-\mathrm{BH}_{4}{ }^{-}$ clusters. ${ }^{38}$ Setting a consistent $\mathrm{Mg}^{2+}$ concentration for DCE and TCE naturally implies a higher concentration of coordinating $\mathrm{Cl}^{-}$ions, which may result in a larger cluster size and hence a lower diffusion coefficient. In the case of TCE, the MeTHF solvent has a lower dielectric constant than THF, implying a poorer ability to solvate $\mathrm{Mg}^{2+}$ cations which may result in a larger $\mathrm{Mg}-\mathrm{Cl}$ type cluster that may impinge on the diffusion properties. ${ }^{26}$ A complete analysis of the complex dynamics in these systems which affect $\mathrm{Mg}^{2+}$ diffusion properties in different electrolytic systems is still required, but for the purposes of our study, consistent $\mathrm{Mg}^{2+}$ concentrations were selected as a basis for examining cation aggregation properties across these three systems.

To further analyse the performance of MCE and DCE, the upper voltage limit was increased to $2 \mathrm{~V}$ (Fig. S3 and S4 $\dagger$ ). In this case, the capacity of the cell with MCE shows a quicker conditioning at the expense of a lower overall capacity which can be attributed to premature decomposition of the electrolyte. From the early charge/discharge cycles of DCE, it is clear that the higher maximum voltage improves the overpotential and enhances the specific capacity of the cell, reaching $87 \mathrm{~mA}$ $\mathrm{h} \mathrm{g}^{-1}$ on the second discharge which is higher than the specific capacity observed with the benchmark [(HMDS) $\mathrm{AlCl}_{3}$ ]$\left[\mathrm{Mg}_{2} \mathrm{Cl}_{3} \cdot 6 \mathrm{THF}\right]^{+}$material $\left(77 \mathrm{~mA} \mathrm{~h} \mathrm{~g}^{-1}\right.$ in Fig. $\left.\mathrm{S} 4 \dagger\right)$. This higher performance is likely due to the increased stability of the electrolyte at higher voltages after conditioning which enables further deintercalation of $\mathrm{Mg}$ ions from the Chevrel cathode material above $1.6 \mathrm{~V}$, without the need to modify the material 
surface as recently reported. ${ }^{39}$ Ex situ PXRD of the cycled cathode in DCE (Fig. S5†) confirms $\mathrm{Mg}^{2+}$ intercalation into the Chevrel crystal structure with a displacement of the Bragg reflections towards higher $d$-spacing and the presence of additional reflections corresponding to the $\mathrm{MgMo}_{6} \mathrm{~S}_{8}$ phase.

A major advantage of $\mathrm{Mg}$-ion batteries over their lithium counterparts is the apparent absence of dendrite formation. Recent studies have explored the influence of $\mathrm{Mg}$ electrolyte nature and composition on the plating topology at the surface of the Mg-metal anode. ${ }^{28,40-42}$ For example, the morphology of $\mathrm{Mg}$ deposition using bis(trifluoromethane)sulfonylimide (TFSI) based electrolytes is driven by the decomposition of TFSI at the electrode surface, which inhibits $\mathrm{Mg}$ growth in some areas due to the formation of a passivating layer and affects the regularity of the plating. ${ }^{42}$ The effect on $\mathrm{Mg}$ deposition with our three electrolyte systems was evaluated by SEM and EDX analysis. While SEM of the cycled magnesium anode shows no evidence for surface dendritic $\mathrm{Mg}$ growth for any of our electrolytes, there are electrolyte-dependant differences observable after 100 cycles (Fig. 6). The surface morphology of $\mathrm{Mg}$ reversible deposition is relatively smooth across all three
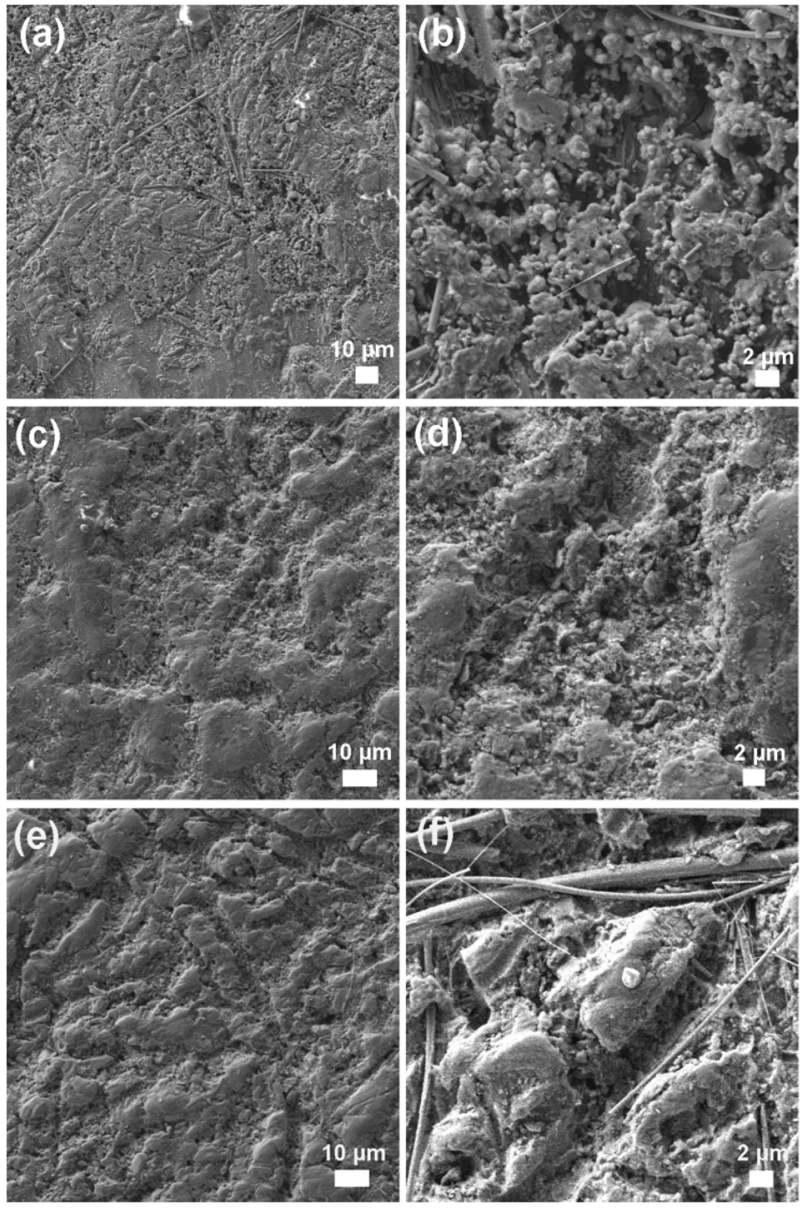

Fig. 6 SEM images of the $\mathrm{Mg}$-metal electrode surface after galvanostatic cycling of the $\mathrm{Mg} / \mathrm{Mo}_{6} \mathrm{~S}_{8}$ cells containing the MCE $(\mathrm{a}, \mathrm{b}), \mathrm{DCE}(\mathrm{c}, \mathrm{d})$ and TCE $(e, f)$ electrolytes. samples, with the presence of small porous cavities which do not compromise the safety of the battery, as well as trapped glass fibres from the glass fibre separator post-cycling. The difference between electrolytes lies in the elemental composition of the deposit identified by EDX mapping. Al deposition is exclusively observed when MCE and DCE are used as electrolytes, but this is not the case with TCE (Fig. S8-S10†). The participation of $\mathrm{Al}$ in the reversible deposition of $\mathrm{Mg}$ in $\mathrm{Mg}$-ion batteries is a phenomenon previously reported in the literature and is not unexpected when considering the more positive reduction potential of $\mathrm{Al}(-1.67 \mathrm{~V}$ vs. NHE) compared to $\mathrm{Mg}$ $(-2.35 \mathrm{~V}$ vs. NHE). Aluminium deposition in rechargeable $\mathrm{Mg}$ ion batteries is associated with a redistribution of the original $\mathrm{Al}: \mathrm{Mg}$ ratio during conditioning. In this case, the $\mathrm{Al}: \mathrm{Mg}$ ratio of $1: 3$ for TCE is likely too deficient in aluminium to allow the $\mathrm{Al}^{3+}$ cations to participate meaningfully in the deposition process. $^{19}$

\section{Conclusions}

The nature of cation aggregation of the electrolyte species has a pronounced effect on the resulting $\mathrm{Mg}$-ion performance and it is clear that developing our understanding of these aggregate species can provide insights into improving these performances. Compared to the more widely observed dinuclear cation $\left[\mathrm{Mg}_{2} \mathrm{Cl}_{3} \cdot 6 \mathrm{THF}\right]^{+}$, the mononuclear cation $\left[\mathrm{MgCl} \cdot \mathrm{Me}_{6} \mathrm{TREN}\right]^{+}$affords higher specific capacity after electrolyte conditioning. The conditioning of MCE is suspected to originate from the presence of the $\mathrm{Me}_{6}$ TREN Lewis donor, whose tetradenticity results in a tighter hold on the $\mathrm{Mg}$ metal centre compared to the monodentate, labile THF ligands. The active redox species in the MCE system is thus likely to be different to the crystallographically characterised species and further in situ investigations are underway to determine the nature of the active species. We attribute the observed greater oxidative stability of the MCE electrolyte over the DCE and TCE species to the formation of weaker Al-N and N-Si bonds. Since the anion species is common across these three systems, this suggests that the anion itself likely undergoes some degree of transformation during cycling. The versatility of $\mathrm{Me}_{6}$ TREN affords the ability to adapt to structural needs owing to its coordinative flexibility arising from the lability of its arms. The $\mathrm{Me}_{6}$ TREN basicity can promote interactions with acidic species, making it our prime eligible suspect for the enhanced MCE oxidative stability. This discovery could be a cornerstone in studying the effect of donor ligands such as $\mathrm{Me}_{6}$ TREN as additives to rechargeable magnesium battery electrolytes to improve their oxidative stability, and enable their application with high voltage cathode materials.

\section{Conflicts of interest}

There are no conflicts to declare. 


\section{Acknowledgements}

We thank the Carnegie Trust for the Universities of Scotland for a Collaborative Research Grant (No. 50425) for generously supporting this research. SC gratefully acknowledges EPSRC funding (EP/N001982/2).

\section{Notes and references}

1 M. Armand and J.-M. Tarascon, Building better batteries, Nature, 2008, 451, 652.

2 D. Larcher and J.-M. Tarascon, Towards greener and more sustainable batteries for electrical energy storage, Nat. Chem., 2015, 7, 19.

3 C. P. Grey and J.-M. Tarascon, Sustainability and in situ monitoring in battery development, Nat. Mater., 2017, 16, 45.

4 J. Muldoon, C. B. Bucur and T. Gregory, Quest for nonaqueous multivalent secondary batteries: magnesium and beyond, Chem. Rev., 2014, 114, 11683.

5 D. Aurbach, Z. Lu, A. Schechter, Y. Gofer, H. Gizbar, R. Turgeman, Y. Cohen, M. Moshkovich and E. Levi, Prototype systems for rechargeable magnesium batteries, Nature, 2000, 407, 724.

6 J. Muldoon, C. B. Bucur and T. Gregory, Fervent Hype behind Magnesium Batteries: An Open Call to Synthetic Chemists-Electrolytes and Cathodes Needed, Angew. Chem., Int. Ed., 2017, 56, 12064.

7 Z. Lu, A. Schechter, M. Moshkovich and D. Aurbach, On the electrochemical behavior of magnesium electrodes in polar aprotic electrolyte solutions, J. Electroanal. Chem., 1999, 466, 203.

8 H. Kuwata, M. Matsui and N. Imanishi, Passivation Layer Formation of Magnesium Metal Negative Electrodes for Rechargeable Magnesium Batteries, J. Electrochem. Soc., 2017, 164, A3229.

9 C. Liebenow, Reversibility of electrochemical magnesium deposition from Grignard solutions, J. Appl. Electrochem., 1997, 27, 221.

10 N. Pour, Y. Gofer, D. T. Major and D. Aurbach, Structural Analysis of Electrolyte Solutions for Rechargeable $\mathrm{Mg}$ Batteries by Stereoscopic Means and DFT Calculations, J. Am. Chem. Soc., 2011, 133, 6270.

11 Z. Zhao-Karger, X. Zhao, O. Fuhr and M. Fichtner, Bisamide based non-nucleophilic electrolytes for rechargeable magnesium batteries, RSC Adv., 2013, 3, 16330.

12 T. Liu, Y. Shao, G. Li, M. Gu, J. Hu, S. Xu, Z. Nie, X. Chen, C. Wang and J. Liu, A facile approach using $\mathrm{MgCl}_{2}$ to formulate high performance $\mathrm{Mg}^{2+}$ electrolytes for rechargeable Mg batteries, J. Mater. Chem. A, 2014, 2, 3430.

13 Z. Zhao-Karger, J. E. Mueller, X. Zhao, O. Fuhr, T. Jacob and $M$. Fichtner, Novel transmetalation reaction for electrolyte synthesis for rechargeable magnesium batteries, $R S C$ Adv., 2014, 4, 26924.
14 H. S. Kim, T. S. Arthur, G. D. Allred, J. Zajicek, J. G. Newman, A. E. Rodnyansky, A. G. Oliver, W. C. Boggess and J. Muldoon, Structure and compatibility of a magnesium electrolyte with a sulphur cathode, Nat. Commun., 2011, 2, 427.

15 E. V. Brouillet, A. R. Kennedy, K. Koszinowski, R. McLellan, R. E. Mulvey and S. D. Robertson, Exposing elusive cationic magnesium-chloro aggregates in aluminate complexes through donor control, Dalton Trans., 2016, 45, 5590.

16 E. G. Nelson, J. W. Kampf and B. M. Bartlett, Enhanced oxidative stability of non-Grignard magnesium electrolytes through ligand modification, Chem. Commun., 2014, 50, 5193.

17 J. Zhu, Y. Guo, J. Yang, Y. Nuli, F. Zhang, J. Wang and S. I. Hirano, Halogen-free boron based electrolyte solution for rechargeable magnesium batteries, J. Power Sources, 2014, 248, 690.

18 T. Liu, J. T. Cox, D. Hu, X. Deng, J. Hu, M. Y. Hu, J. Xiao, Y. Shao, K. Tang and J. Liu, A fundamental study on the $\left[(\mu-\mathrm{Cl})_{3} \mathrm{Mg}_{2}(\mathrm{THF})_{6}\right]^{+}$dimer electrolytes for rechargeable $\mathrm{Mg}$ batteries, Chem. Commun., 2015, 51, 2312.

19 C. J. Barile, E. C. Barile, K. R. Zavadil, R. G. Nuzzo and A. A. Gewirth, Electrolytic Conditioning of a Magnesium Aluminum Chloride Complex for Reversible Magnesium Deposition, J. Phys. Chem. C, 2014, 118, 27623.

20 S. He, K. V. Nielson, J. Luo and T. L. Liu, Recent advances on $\mathrm{MgCl}_{2}$ based electrolytes for rechargeable $\mathrm{Mg}$ batteries, Energy Storage Mater., 2017, 8, 184.

21 P. Canepa, G. Sai Gautam, D. C. Hannah, R. Malik, M. Liu, K. G. Gallagher, K. A. Persson and G. Ceder, Odyssey of Multivalent Cathode Materials: Open Questions and Future Challenges, Chem. Rev., 2017, 117, 4287.

22 X. Sun, P. Bonnick, V. Duffort, M. Liu, Z. Rong, K. A. Persson, G. Ceder and L. F. Nazar, A high capacity thiospinel cathode for $\mathrm{Mg}$ batteries, Energy Environ. Sci., 2016, 9, 2273.

23 M. Á. Fuentes, A. Zabala, A. R. Kennedy and R. E. Mulvey, Structural Diversity in Alkali Metal and Alkali Metal Magnesiate Chemistry of the Bulky 2,6-Diisopropyl- $N$-(trimethylsilyl)anilino Ligand, Chem. - Eur. J., 2016, 22, 14968.

24 I. Shterenberg, M. Salama, H. D. Yoo, Y. Gofer, J.-B. Park, Y.-K. Sun and D. Aurbach, Evaluation of $\left(\mathrm{CF}_{3} \mathrm{SO}_{2}\right)_{2} \mathrm{~N}^{-}$(TFSI) Based Electrolyte Solutions for $\mathrm{Mg}$ Batteries, J. Electrochem. Soc., 2015, 162, A7118.

25 K. A. See, K. W. Chapman, L. Zhu, K. M. Wiaderek, O. J. Borkiewicz, C. J. Barile, P. J. Chupas and A. A. Gewirth, The Interplay of $\mathrm{Al}$ and $\mathrm{Mg}$ Speciation in Advanced $\mathrm{Mg}$ Battery Electrolyte Solutions, J. Am. Chem. Soc., 2016, 138, 328.

26 P. Canepa, S. Jayaraman, L. Cheng, N. N. Rajput, W. D. Richards, G. S. Gautam, L. A. Curtiss, K. A. Persson and G. Ceder, Elucidating the structure of the magnesium aluminum chloride complex electrolyte for magnesium-ion batteries, Energy Environ. Sci., 2015, 8, 3718.

27 K. A. See, Y.-M. Liu, Y. Ha, C. J. Barile and A. A. Gewirth, Effect of Concentration on the Electrochemistry and 
Speciation of the Magnesium Aluminum Chloride Complex Electrolyte Solution, ACS Appl. Mater. Interfaces, 2017, 9, 35729.

28 M. S. Ding, T. Diemant, R. Jürgen Behm, S. Passerini and G. A. Giffin, Dendrite Growth in $\mathrm{Mg}$ Metal Cells Containing $\mathrm{Mg}(\mathrm{TFSI})_{2} /$ Glyme Electrolytes, J. Electrochem. Soc., 2018, 165, A1983.

29 R. Davidson, A. Verma, D. Santos, F. Hao, C. Fincher, S. Xiang, J. Van Buskirk, K. Xie, M. Pharr, P. P. Mukherjee and S. Banerjee, Formation of Magnesium Dendrites during Electrodeposition, ACS Energy Lett., 2019, 4, 375.

30 P. Canepa, G. S. Gautam, R. Malik, S. Jayaraman, Z. Rong, K. R. Zavadil, K. Persson and G. Ceder, Understanding the Initial Stages of Reversible Mg Deposition and Stripping in Inorganic Nonaqueous Electrolytes, Chem. Mater., 2015, 27, 3317.

31 J. H. Ha, B. Adams, J.-H. Cho, V. Duffort, J. H. Kim, K. Y. Chung, B. W. Cho, L. F. Nazar and S. H. Oh, A conditioning-free magnesium chloride complex electrolyte for rechargeable magnesium batteries, J. Mater. Chem. A, 2016, 4, 7160 .

32 T. Cadenbach, E. Hevia, A. R. Kennedy, R. E. Mulvey, J.-A. Pickrell and S. D. Robertson, Accessing low denticity coordination modes of a high denticity tripodal ligand to complete its coordinative repertoire, Dalton Trans., 2012, 41, 10141.

33 D. R. Armstrong, M. G. Davidson, D. Garcia-Vivo, A. R. Kennedy, R. E. Mulvey and S. D. Robertson, Monomerizing alkali-metal 3,5-dimethylbenzyl salts with tris (N, N-dimethyl-2-aminoethyl)amine ( $\left.\mathrm{Me}_{6} \mathrm{TREN}\right)$ : structural and bonding implications, Inorg. Chem., 2013, 52, 12023.

34 D. R. Armstrong, C. M. M. Harris, A. R. Kennedy, J. J. Liggat, R. McLellan, R. E. Mulvey, M. D. T. Urquhart and S. D. Robertson, Developing lithium chemistry of 1,2dihydropyridines: from kinetic intermediates to isolable characterized compounds, Chem. - Eur. J., 2015, 21, 14410.
35 M. D. Levi, E. Lancry, H. Gizbar, Z. Lu, E. Levi, Y. Gofer and D. Aurbach, Kinetic and Thermodynamic Studies of $\mathrm{Mg}^{2+}$ and $\mathrm{Li}^{+}$Ion Insertion into the $\mathrm{Mo}_{6} \mathrm{~S}_{8}$ Chevrel Phase, J. Electrochem. Soc., 2004, 151, A1044.

36 M. D. Levi, H. Gizbar, E. Lancry, Y. Gofer, E. Levi and D. Aurbach, A comparative study of $\mathrm{Mg}^{2+}$ and $\mathrm{Li}^{+}$ion insertions into the $\mathrm{Mo}_{6} \mathrm{~S}_{8}$ Chevrel phase using electrochemical impedance spectroscopy, J. Electroanal. Chem., 2004, 569, 211.

37 J. Richard, A. Benayad, J. F. Colin and S. Martinet, Charge Transfer Mechanism into the Chevrel Phase $\mathrm{Mo}_{6} \mathrm{~S}_{8}$ during Mg Intercalation, J. Phys. Chem. C, 2017, 121, 17096.

38 D. Samuel, C. Steinhauser, J. G. Smith, A. Kaufman, M. D. Radin, J. Naruse, H. Hiramatsu and D. J. Siegel, Ion Pairing and Diffusion in Magnesium Electrolytes Based on Magnesium Borohydride, ACS Appl. Mater. Interfaces, 2017, 9, 43755 .

39 D. Muthuraj and S. Mitra, Reversible $\mathrm{Mg}$ insertion into chevrel phase $\mathrm{Mo}_{6} \mathrm{~S}_{8}$ cathode: Preparation, electrochemistry and X-ray photoelectron spectroscopy study, Mater. Res. Bull., 2018, 101, 167.

40 S. Y. Ha, Y. W. Lee, S. W. Woo, B. Koo, J. S. Kim, J. Cho, K. T. Lee and N. S. Choi, Magnesium(II) bis(trifluoromethane sulfonyl) imide-based electrolytes with wide electrochemical windows for rechargeable magnesium batteries, ACS Appl. Mater. Interfaces, 2014, 6, 4063.

41 R. E. Doe, R. Han, J. Hwang, A. J. Gmitter, I. Shterenberg, H. D. Yoo, N. Pour and D. Aurbach, Novel, electrolyte solutions comprising fully inorganic salts with high anodic stability for rechargeable magnesium batteries, Chem. Commun., 2014, 50, 243.

42 H. D. Yoo, S.-D. Han, I. L. Bolotin, G. M. Nolis, R. D. Bayliss, A. K. Burrell, J. T. Vaughey and J. Cabana, Degradation Mechanisms of Magnesium Metal Anodes in Electrolytes Based on $\left(\mathrm{CF}_{3} \mathrm{SO}_{2}\right)_{2} \mathrm{~N}^{-}$at High Current Densities, Langmuir, 2017, 33, 9398. 